\title{
Photocatalytic Degradation of Reactive Dyes in Effluents Employing Copper Doped Titanium Dioxide Nanocrystals and Direct Sunlight
}

\author{
P. DHARMARAJAN ${ }^{\mathrm{a}}$, A. SABASTIYAN ${ }^{\mathrm{b}}$, M. YOSUVA SUVAIKIN ${ }^{\mathrm{b} *}$, \\ S. TITUS ${ }^{\mathrm{b}}$ and C. MUTHUKUMAR ${ }^{\mathrm{c}}$
}

${ }^{a}$ Department of Chemistry, Thanthai Hans Roever College, Perambalur - 621 212, India

${ }^{\mathrm{b}}$ Department of Chemistry, Urumu Dhanalakshmi College, Tiruchirappalli- 620019, India

${ }^{c}$ Department of Chemistry, J.J.College of Arts and Science, Pudukkottai-622001, India

yosu77s@gmail.com

Received 3 March 2013 / Accepted 19 March 2013

\begin{abstract}
Nanosized photocatalyst samples of $\mathrm{TiO}_{2}$ and $\mathrm{Cu}$-doped $\mathrm{TiO}_{2}$ were synthesized employing sol-gel method. The photocatalysts were characterized by powder XRD, SEM, EDAX and diffused reflectance spectral studies. Model effluents of reactive dyes were subjected to degradation employing the $\mathrm{Cu}$-doped $\mathrm{TiO}_{2}$ catalysts with direct sunlight irradiation and liberal aeration. The heterogeneous Advanced Oxidation Process (AOP) involves photolytic generation of very reactive hydroxyl radicals. The photocatalytic degradation activity of the nanocatalysts has been evaluated on the basis of Langmuir-Hinshelwood kinetic model. The effects of $\mathrm{pH}$, concentration of $\mathrm{H}_{2} \mathrm{O}_{2}$ added, initial dye concentration and dosage of the catalyst have also been investigated. The degrees of degradation/mineralization of the organic dyes have also been estimated by measuring the CODs of the photocatalytically degraded dye solutions. The results show that the $\mathrm{Cu}$-doped $\mathrm{TiO}_{2}$ nanoparticles are very effective in degrading the dye pollutants.
\end{abstract}

Keywords: $\mathrm{Cu}$-doped $\mathrm{TiO}_{2}$ nanocrystals, Reactive dyes, Photocatalytic degradation, Advanced oxidation process, Hydroxyl radical, Chemical oxygen demand

\section{Introduction}

Environmental concerns have led to extensive research on the removal of organic compounds from industrial waste streams. Effluents from industries released into the environment cause many serious ecological problems. Textile industry is one generating large volumes of toxic waste water containing commercial dyes which are carcinogenic in nature. Heterogeneous advanced oxidation processes which involve hydroxyl radicals $(\cdot \mathrm{OH})$ are successfully used to degrade and mineralize organic pollutants ${ }^{1,2}$ present in waste waters into $\mathrm{CO}_{2}$ and inorganic ions. Metal oxide semiconductors have been used as photocatalysts ${ }^{3,4}$ in the oxidation processes. $\mathrm{TiO}_{2}$-mediated photocatalytic oxidation appears to be a promising technique for degradation of commercial dyes. Some metal ion doped $\mathrm{TiO}_{2}$ is reported to have 
better activity than the undoped $\mathrm{TiO}_{2}$. In view of this, an attempt has been made to synthesize solar light active nanocrystals of $\mathrm{Cu}$-doped $\mathrm{TiO}_{2}$ for photocatalytic degradation of reactive dyes present in waste waters. $\mathrm{TiO}_{2}$ is relatively cheap and non-toxic when compared to others. Physical modification of $\mathrm{TiO}_{2}$ into nanoparticles has shown photocatalytic activity improvement to a large extent. Many researchers have synthesized visible light active anatase and rutile titania by doping transition metal ions such as $\mathrm{Fe}^{3+}, \mathrm{Mo}^{5+}, \mathrm{Ru}^{3+}, \mathrm{V}^{4+}$ and $\mathrm{Rh}^{4+}$ or nonmetals like $\mathrm{N}, \mathrm{C}, \mathrm{F}, \mathrm{P}$ and $\mathrm{S}$ to narrow the band gap. Noble metal ion doping ( $\mathrm{Pt}$, $\mathrm{Au}, \mathrm{Pd} \mathrm{Ag}$ etc.) has also been reported to be effective for enhancement of $\mathrm{TiO}_{2}$ photocatalysis $^{5-9}$.

Reactive dyes are the single largest group of dyes used in textile industry. They have been chosen for the photocatalytic degradation studies over $\mathrm{Cu}$-doped $\mathrm{TiO}_{2}$ because it is very difficult to eliminate them by the usual biodegradation and sludge absorption techniques.

\section{Experimental}

Industrial grade reactive blue $4\left(\mathrm{Na}_{2} \mathrm{C}_{23} \mathrm{H}_{12} \mathrm{~N}_{6} \mathrm{O}_{8} \mathrm{~S}_{2} \mathrm{Cl}_{2}, \lambda_{\max }=598 \mathrm{~nm}\right)$, reactive orange 30 $\left(\mathrm{Na}_{4} \mathrm{C}_{29} \mathrm{H}_{13} \mathrm{~N}_{5} \mathrm{O}_{13} \mathrm{~S}_{4} \mathrm{Cl}_{2}, \lambda_{\max }=422 \mathrm{~nm}\right)$, reactive red $120\left(\mathrm{Na}_{6} \mathrm{C}_{44} \mathrm{H}_{24} \mathrm{~N}_{14} \mathrm{O}_{20} \mathrm{~S}_{6} \mathrm{Cl}_{2}, \lambda_{\max }=515 \mathrm{~nm}\right)$ and reactive black $5\left(\mathrm{Na}_{4} \mathrm{C}_{26} \mathrm{H}_{21} \mathrm{~N}_{5} \mathrm{O}_{19} \mathrm{~S}_{6}, \lambda_{\max }=602 \mathrm{~nm}\right)$ supplied by Vexent Dyeanx India Pvt Ltd., Mumbai were used for preparation of model effluents in distilled water, $\mathrm{TiCl}_{4}$ (99.5\% pure) supplied by Loba Chemie Pvt Ltd. was used for the preparation of $\mathrm{TiO}_{2}$ photocatalyst. Other AR grade chemicals such as copper(II) acetate monohydrate, potassium dichromate, mercury(II) sulphate, silver(I) sulphate, ferrous ammonium sulphate(FAS) and ferroin indicator purchased from Qualigens were used as such.

An advanced Bruker AXS D8 diffractometer was used to obtain powder diffraction patterns of the photocatalyst samples. A scanning electron microscope JEOL Model JSM$6390 \mathrm{LV}$ was used to analyze the surface morphology of the catalytic samples. Energy dispersed X-ray diffraction analysis (EDAX) was performed employing JEOL Model JED2300 EDS analyzer. Diffuse reflectance spectral data were collected over the spectral range 300-800nm with a Perkin - Elmer Lambda 2D equipped with a $5 \mathrm{~cm}$ integrating sphere (Lab sphere). $\mathrm{MgO}$ was used as the reference material. Concentrations of the dye solutions were determined periodically by measuring absorbance at the respective $\lambda_{\max }$ values using an Elico-SL-171 visible spectrophotometer.

\section{Preparation of copper-doped $\mathrm{TiO}_{2}$ photocatalyst samples}

$\mathrm{TiO}_{2}$ and $\mathrm{Cu}$-doped $\mathrm{TiO}_{2}$ samples were synthesized using sol-gel method as reported elsewhere ${ }^{10}$. In a typical synthesis, $5 \mathrm{~mL}$ of $\mathrm{TiCl}_{4}$ was added to $250 \mathrm{~mL}$ of ice cold distilled water with vigorous stirring over a period of half an hour. The hydrolysis reaction gave a colloidal solution indicating the formation of nano-sized $\mathrm{TiO}_{2}$ particles. (The hydrolysis of $\mathrm{TiCl}_{4}$ could be expressed as: $\mathrm{TiCl}_{4}+2 \mathrm{H}_{2} \mathrm{O} \rightarrow \mathrm{TiO}_{2}+4 \mathrm{H}^{+}+4 \mathrm{Cl}^{-}$) By adding ammonia solution, $\mathrm{H}^{+}$ions were neutralized and flocculation of $\mathrm{TiO}_{2}$ was effected. The precipitate was separated centrifugally and washed several times with distilled water.

In the process of copper doping, copper acetate in the respective molar ratio $(\mathrm{Cu} / \mathrm{Ti}=$ $0.02,0.04,0.06,0.08$ and 0.1 ) was mixed with the $\mathrm{TiO}_{2}$ gel and stirred with a magnetic stirrer for two hours for uniform dispersion. In each case the gel was dried at $100{ }^{\circ} \mathrm{C}$ to remove water and the dried solid was ground in an agate mortar and pressed into a ceramic crucible and finally calcined at $500{ }^{\circ} \mathrm{C}$ in a muffle furnace for completion of solid phase reactions. 


\section{Results and Discussion}

\section{Physicochemical Characterization of Photocatalytic Samples}

\section{$X$-Ray Diffraction Studies}

The crystalline structures of calcined samples were determined by analyzing the powder XRD patterns recorded at room temperature with $\mathrm{Cu} \mathrm{K \alpha}$ radiation. Measurements were made in steps of $0.025^{\circ}$ with count time of $2 \mathrm{~s}$ in the range of $20-65^{\circ}$. The phases were identified with the aid of JCPDS files ${ }^{11}$. From the full width at half maximum (FWHM) of the diffraction pattern the crystallite size was calculated in each case using Scherrer's equation ${ }^{12}$.

$$
\text { Crystallite size }=\mathrm{K} \lambda / \mathrm{W} \cos \theta
$$

Where shape factor, $\mathrm{K}=0.89$ and $\mathrm{W}=$ full width at half maximum peak. The powder XRD patterns of $\mathrm{TiO}_{2}$ and $\mathrm{Cu}$-doped $\mathrm{TiO}_{2}$ are shown in Figure 1. The XRD patterns show that the major peaks are of anatase phase manifested by (101) planes at $2 \theta=25.5^{\circ}$. The (110) peak expected for rutile at $2 \theta=27.5^{\circ}$ is not present in any of the patterns indicating the absence of rutile phase. The peaks of anatase $\mathrm{TiO}_{2}$ for the $\mathrm{Cu}$-doped ones are broader than that of the undoped $\mathrm{TiO}_{2}$. The average crystallite sizes calculated for different proportions of $\mathrm{Cu}$ using the Scherrer's equation from the (101) reflections of anatase are listed in Table 1 . The mean crystallite size of the $\mathrm{Cu}$-doped $\mathrm{TiO}_{2}$ decreases as the proportion of $\mathrm{Cu}$ increases. Similar results of decrease of crystallite size by doping with several transition metals on $\mathrm{TiO}_{2}$ are already reported. However the bulk crystalline structure remains virtually unchanged by the incorporation of dopant metals ${ }^{13}$.

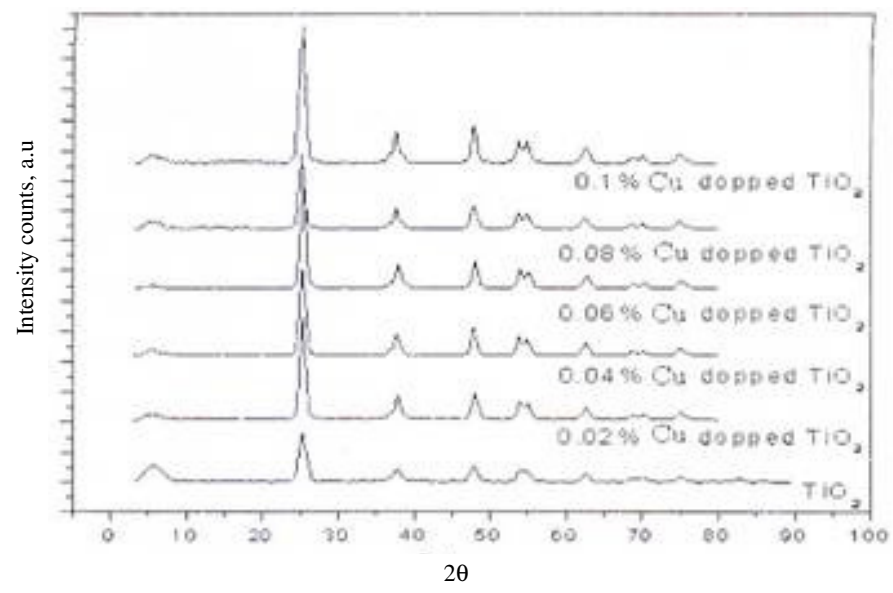

Figure1. X-ray diffraction patterns of $\mathrm{TiO}_{2}$ and $\mathrm{Cu}$-doped $\mathrm{TiO}_{2}$

Table 1. Effect of $\mathrm{Cu}$ doping on the crystallite Size of $\mathrm{TiO}_{2}$

\begin{tabular}{cccc}
\hline S.No & Photocatalyst & $\begin{array}{c}\text { Full width half maximum for } \\
(101) \text { diffraction (in degrees) }\end{array}$ & $\begin{array}{c}\text { Crystallite size } \\
\text { nm }\end{array}$ \\
\hline 1. & $\mathrm{TiO}_{2}$ & 0.551 & 44.9 \\
2. & $0.02 \% \mathrm{Cu}$-doped $\mathrm{TiO}_{2}$ & 0.611 & 40.5 \\
3. & $0.04 \% \mathrm{Cu}$-doped $\mathrm{TiO}_{2}$ & 0.671 & 36.9 \\
4. & $0.06 \% \mathrm{Cu}$-doped $\mathrm{TiO}_{2}$ & 0.673 & 36.8 \\
5. & $0.08 \% \mathrm{Cu}$-doped $\mathrm{TiO}_{2}$ & 0.700 & 35.3 \\
6. & $0.1 \% \mathrm{Cu}$-doped $\mathrm{TiO}_{2}$ & 0.765 & 32.3 \\
\hline
\end{tabular}




\section{SEM and EDAX investigations on catalytic samples}

In SEM photographs, both undoped $\mathrm{TiO}_{2}$ and $\mathrm{Cu}$-doped $\mathrm{TiO}_{2}$ are found to exist as irregular agglomerates (Figure 2). But the $\mathrm{Cu}$-doped $\mathrm{TiO}_{2}$ samples are less agglomerated than the undoped $\mathrm{TiO}_{2}$, indicating inhibition of agglomeration of $\mathrm{TiO}_{2}$ nanoparticles by $\mathrm{Cu}^{\mathrm{II}}$ ions. Lower level of agglomeration has been reported for the doping of $\mathrm{Au}$ on $\mathrm{TiO}_{2}{ }^{14}$. The lower agglomeration of $\mathrm{Cu}$-doped $\mathrm{TiO}_{2}$ nanoparticles may be the inducement for a higher photocatalytic activity. The energy dispersive $\mathrm{X}$-ray spectroscopic analyses of the $\mathrm{Cu}$-doped $\mathrm{TiO}_{2}$ also confirm the presence of $\mathrm{Cu}^{\mathrm{II}}$ ions in the prepared photocatalysts.

(a)

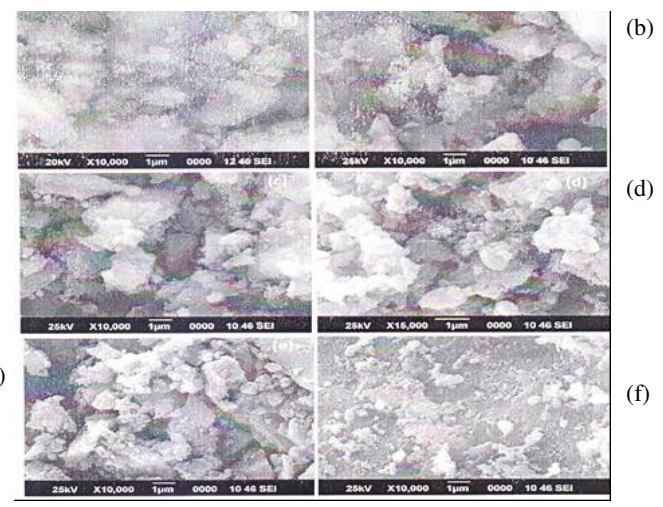

Figure 2. SEM images (a) $\mathrm{TiO}_{2}$, (b) $0.02 \% \mathrm{Cu}$-doped $\mathrm{TiO}_{2}$, (c) $0.04 \% \mathrm{Cu}$-doped $\mathrm{TiO}_{2}$, (d) $0.06 \% \mathrm{Cu}$-doped $\mathrm{TiO}_{2}$, (e) $0.08 \% \mathrm{Cu}$-doped $\mathrm{TiO}_{2}$ and (f) $0.1 \% \mathrm{Cu}$-doped $\mathrm{TiO}_{2}$

\section{Diffuse reflectance spectral studies}

Diffuse reflectance UV-visible spectra of $\mathrm{TiO}_{2}$ and $\mathrm{Cu}$-doped $\mathrm{TiO}_{2}$ samples have been recorded to analyze the effect of doping with $\mathrm{Cu}^{\mathrm{II}}$ ion on the absorption edge and optical band gap of $\mathrm{TiO}_{2}$. The band gaps have been deduced from the Tauc plots. Tauc plot in each case is a plot of $[\mathrm{F}(\mathrm{R}) \mathrm{h} v]^{1 / 2}$ versus photon energy (As representative cases the Tauc plots obtained for undoped $\mathrm{TiO}_{2}$ and $0.02 \% \mathrm{Cu}$-doped $\mathrm{TiO}_{2}$ are shown in Figures $3 \mathrm{a}$ and $3 \mathrm{~b}$ ). From the Tauc plots, the band gap energy values obtained are 3.19, 3.17, 3.16, 3.14, 3.12 and $3.11 \mathrm{eV}$ respectively for undoped, $0.02,0.04,0.06,0.08$ and $0.1 \% \mathrm{Cu}$-doped $\mathrm{TiO}_{2}$ nanoparticles. This shows that the proportion of $\mathrm{Cu}$ dopant narrows down the band gap energy of the $\mathrm{TiO}_{2}$.

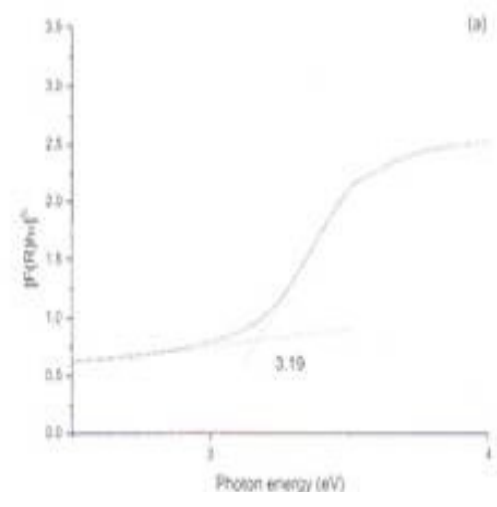

Figure 3a. Tauc plot for the diffuse reflectance data of $\mathrm{TiO}_{2}$

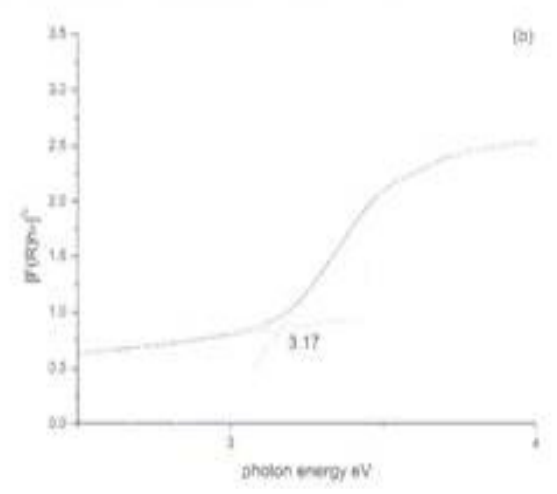

Figure 3b. Tauc plot for the diffuse reflectance data of $0.02 \% \mathrm{Cu}$ - doped $\mathrm{TiO}_{2}$ 


\section{Studies on photocatalytic degradation of reactive dyes}

All the dye degradation experiments were performed during clear sky days in summer period of 2012 under direct sunlight. In a typical experiment $50 \mathrm{~mL}$ of a dye solution was taken with $50 \mathrm{mg}$ of the photocatalyst in a $250 \mathrm{~mL}$ glass beaker. The experimental set up was kept under direct sunlight with continuous aeration. The concentrations of the dye remaining (undegraded) were determined periodically by measuring the light absorbance at the $\lambda_{\max }$ of the particular dye. In order to avoid variation in results due to fluctuation in the intensity of sunlight, a triplicate set of experiments was carried out simultaneously and the average of the results was noted.

To study the effect of $\mathrm{pH}$ of a dye solution on the photocatalytic degradation, the $\mathrm{pH}$ values of the dye solution were modified to different values $(3,5,7,9$ and 12) by using $0.1 \mathrm{M} \mathrm{HCl}$ and $0.1 \mathrm{M} \mathrm{NaOH}$ solutions.

\section{Photocatalytic degradation activity evaluation}

The evaluation of activities of catalysts with reference to reactive blue 4 is discussed in detail. The degradation of reactive blue 4 as a function time is shown in Figure 4a. Analysis of the curves was carried out with the Langmuir - Hinshelwood kinetic model:

$$
\mathrm{r}=\mathrm{kKC} /(1+\mathrm{KC}) \text {, }
$$

Where $\mathrm{r}$ is the specific degradation reaction rate of the dye $\left(\mathrm{mg} \mathrm{L}^{-1} \mathrm{~min}^{-1}\right), \mathrm{C}$ is the concentration of the dye $\left(\mathrm{mgL}^{-1}\right), \mathrm{k}$ is the rate constant $\left(\mathrm{s}^{-1}\right)$ and $\mathrm{K}$ is the dye adsorption constant. When $\mathrm{C}$ is small the above equation is simplified into an apparent first order rate equation ${ }^{15}$.

$$
-\mathrm{dc} / \mathrm{dt}=\mathrm{r}=\mathrm{kKC}=\mathrm{k}_{\mathrm{app}} \mathrm{C}
$$

This equation on integration gives $-\ln C / C_{0}=k_{a p p} t$ where $C_{0}$ is the initial concentration of the dye, $\mathrm{C}$ is the concentration of the dye after $\mathrm{t}$ minutes of illumination. The data obtained fit well into the pseudo first order rate equation as shown in Figure $4 \mathrm{~b}$ and the rate constant values are listed in Table 2 . The results show that rate constant values for the degradation of reactive blue 4 increase with the concentration of the $\mathrm{Cu}$ dopant upto $0.04 \%$ and further increase of $\mathrm{Cu}$ doping decreases the rate constants. It indicates that $0.04 \% \mathrm{Cu}$ doping is optimum for maximum activity of $\mathrm{TiO}_{2}$. The dopant sites act as recombination centres when the concentration exceeds the optimum level ${ }^{16}$, which leads to reduction in the photocatalytic activity

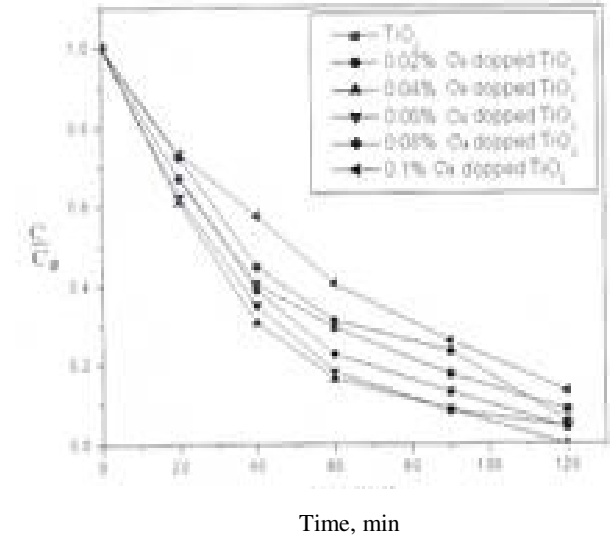

Figure 4a. Concentration Vs. time plots for photocatalytic degradation of reactive blue 4

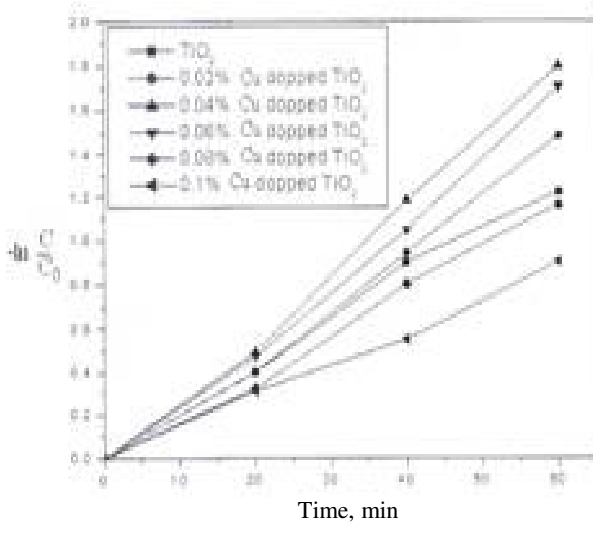

Figure 4b. Pseudo first order kinetic plots for the degradation of reactive blue 4 
Table 2. Pseudo first order rate constant values for degradation of reactive blue 4 over $\mathrm{TiO}_{2}$ and $\mathrm{Cu}$-doped $\mathrm{TiO}_{2}$

\begin{tabular}{ccc}
\hline Photocatalyst & Pseudo first order rate constant, $\mathrm{k}$ & $\mathrm{R}^{2}$ \\
\hline $\mathrm{TiO}_{2}$ & 0.0268 & 0.996 \\
$0.02 \% \mathrm{Cu}$-doped $\mathrm{TiO}_{2}$ & 0.0347 & 0.995 \\
$0.04 \% \mathrm{Cu}$-doped $\mathrm{TiO}_{2}$ & 0.03689 & 0.997 \\
$0.06 \% \mathrm{Cu}$-doped $\mathrm{TiO}_{2}$ & 0.0310 & 0.995 \\
$0.08 \% \mathrm{Cu}$-doped $\mathrm{TiO}_{2}$ & 0.0288 & 0.993 \\
$0.1 \% \mathrm{Cu}$-doped $\mathrm{TiO}_{2}$ & 0.0239 & 0.992 \\
\hline
\end{tabular}

\section{Effect of $\mathrm{pH}$ of the dye solution on photocatalytic activity}

The variation of solution $\mathrm{pH}$ changes the surface of the $\mathrm{TiO}_{2}$ nanoparticles and shifts the potential of the catalytic reaction. Under acidic $\mathrm{pH}$ surface of titania is protonated and remains positively charged. Under alkaline condition the surface is deprotonated and remains negatively charged. Under acidic conditions, the positively charged catalytic surface could adsorb strongly the dye anions. This facilitates the hydroxyl radicals to attack the dye molecules more easily ${ }^{17}$. But in alkaline condition adsorption of dye on the $\mathrm{TiO}_{2}$ surface decreases because of the repulsion between negatively charged catalytic surface and dye anions resulting in a decrease of photocatalytc degradation rate ${ }^{18}$. Thus the effect of change of $\mathrm{pH}$ on the photocatalytic degradation of Reactive Blue 4 is shown in Figure 5.

The photocatalytic degradation of reactive blue 4 has been studied at different $\mathrm{H}_{2} \mathrm{O}_{2}$ concentrations and the results are summarized in Figure 6. The degradation of the dye increases with increasing $\mathrm{H}_{2} \mathrm{O}_{2}$ concentration up to $0.001 \mathrm{M}$, the optimum load ${ }^{19}$.

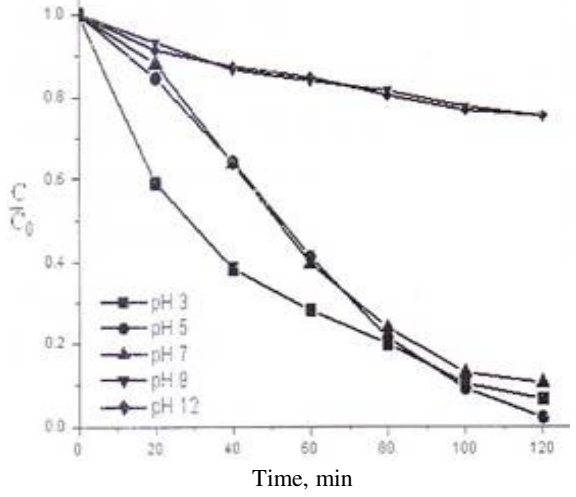

Figure 5. Effect of $\mathrm{pH}$ on photocatalytic degradation of reactive blue 4 on $0.1 \% \mathrm{Cu}$ doped $\mathrm{TiO}_{2}$

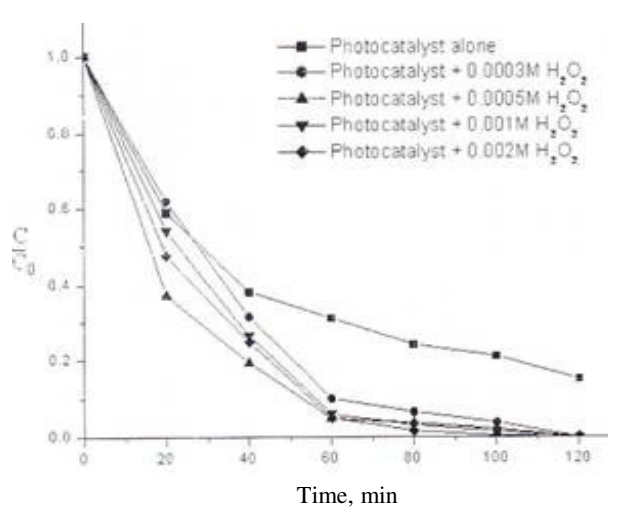

Figure 6. Effect of concentration of $\mathrm{H}_{2} \mathrm{O}_{2}$ on photocatalytic degradation of reactive blue 4 on $\mathrm{Cu}$-doped $\mathrm{TiO}_{2}$

\section{Effect of concentration of hydrogen peroxide}

Oxygen is the primary acceptor of the conduction band (CB) electron with the formation of superoxide radical anion. $\mathrm{H}_{2} \mathrm{O}_{2}$ can compensate for the $\mathrm{O}_{2}$ lack and play a role as an external electron scavenger. It can trap the photogenerated CB electron, thus inhibiting the electronhole recombination and producing hydroxyl radicals as shown here

$$
\mathrm{e}^{-}(\mathrm{CB})+\mathrm{H}_{2} \mathrm{O}_{2} \rightarrow{ }^{\circ} \mathrm{OH}+\mathrm{OH}^{-}
$$


$\mathrm{H}_{2} \mathrm{O}_{2}$ may also be photolysed to produce $\mathrm{OH}^{\cdot}$ radical directly $\left(\mathrm{H}_{2} \mathrm{O}_{2} \rightarrow 2 \cdot \mathrm{OH}\right)$. But $\mathrm{H}_{2} \mathrm{O}_{2}$ has extremely low absorption of solarlight. Hence oxidative degradation of the dye beyond optimum load of $\mathrm{H}_{2} \mathrm{O}_{2}$ is insignificant. The inhibition of degradation of the dye beyond optimum load of $\mathrm{H}_{2} \mathrm{O}_{2}$ may be due to the hydroxyl radical scavenging effect of $\mathrm{H}_{2} \mathrm{O}_{2}$. The hydroperoxy radicals formed are much less reactive and do not involve in oxidative degradation of the dye.

\section{Effect of dye concentration}

The influence of initial concentration of dye solution on degradation efficiency with time is shown in Figure 7. Increasing concentration of the dye solution decreases the percentage of degradation of the dye. As initial concentration increases more dye molecules are adsorbed on $\mathrm{TiO}_{2}$ surface thereby reducing the generation of hydroxyl radicals. As the formation of $\mathrm{OH}$ radicals decreases the percentage degradation of the dye also decreases ${ }^{20-22}$.

\section{Effect of dosage of the catalysts}

The dye degradation increases with increasing catalyst concentration from $0.5 \mathrm{gL}^{-1}$ to $1 \mathrm{gL}^{-1}$. This is characteristic of the heterogeneous photocatalysis. The increase in catalyst amount actually increases the number of active sites on the catalytic surface causing an increase in the number of $\mathrm{OH}$ radicals which really take part in degradation of dye molecules. There is no significant improvement in the rate of degradation of dye when the dosage is above $1 \mathrm{gL}^{-1}$. Beyond $1 \mathrm{gL}^{-1}$ level the solution becomes turbid and a portion of light radiation is blocked ${ }^{23}$. The results are shown in Figure 8.

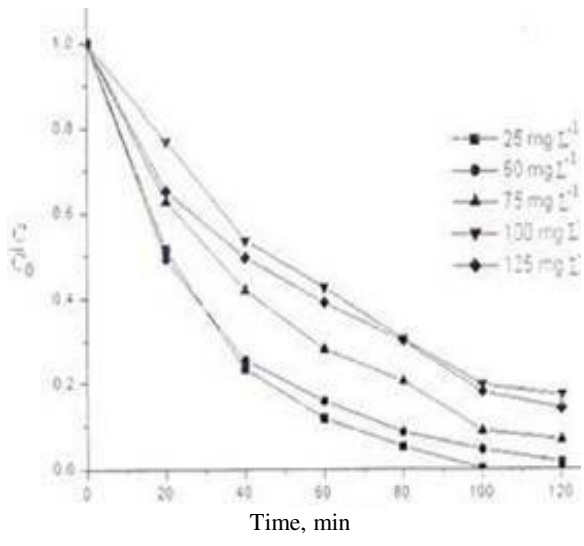

Figure 7. Effect of concentration of reactive blue 4 on photocatalytic degradation by $\mathrm{Cu}$ doped $\mathrm{TiO}_{2}$

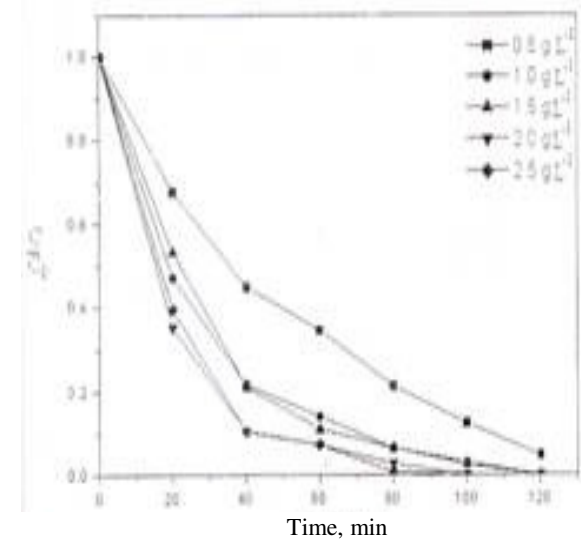

Figure 8. Effect of dosage of Cu-doped $\mathrm{TiO}_{2}$ on photocatalytic degradation of reactive blue 4

\section{Photocatalytic degradations of other reactive dyes}

The degradations of three more reactive dyes viz. Reactive red 120, reactive black 5 and reactive orange 30 were also studied. The initial concentration of the dye solution used was $50 \mathrm{mgL}^{-1}$ and $\mathrm{pH}$ was 5 . The concentrations of the photocatalyst and oxidant were $1 \mathrm{gL}^{-1}$ and $0.01 \mathrm{M}$ respectively. The results show that the degradation of all the three dyes on $\mathrm{Cu}$-doped $\mathrm{TiO}_{2}$ is faster than that on $\mathrm{TiO}_{2}$. The $\mathrm{Cu}$-doped $\mathrm{TiO}_{2}$ completely degraded all the three dyes $\left(50 \mathrm{mgL}^{-1}\right)$ in 120 minutes with solar light irradiation. 


\section{Chemical oxygen demand (COD) analysis}

COD is widely measured to estimate the level of organic load in the waste water and also to estimate the degree of degradation/ mineralization of organic pollutants in waste water treatments. The organic load is measured in terms of total quantity oxygen required to oxidize it into $\mathrm{CO}_{2}$ and water. To measure $\mathrm{COD}$, to $20 \mathrm{~mL}$ of the degraded dye solution taken in a $250 \mathrm{~mL}$ round bottomed flask, $0.4 \mathrm{~g}$ of $\mathrm{Hg} \mathrm{SO}$ and $10 \mathrm{~mL}$ of $0.25 \mathrm{~N} \mathrm{~K}_{2} \mathrm{Cr}_{2} \mathrm{O}_{7}$ solution were added and mixed well. Then $30 \mathrm{~mL}$ of $\mathrm{H}_{2} \mathrm{SO}_{4}, \mathrm{AgSO}_{4}$ reagent $\left(0.5 \mathrm{~g} \mathrm{AgSO}_{4}\right.$ in $30 \mathrm{~mL}$ of Conc. $\mathrm{H}_{2} \mathrm{SO}_{4}$ ) was added slowly with constant stirring and the mixture refluxed for $2 \mathrm{~h}$. The mixture was cooled, diluted to $150 \mathrm{~mL}$ with distilled water and titrated against $0.25 \mathrm{~N}$ ferrous ammonium sulphate (FAS) solution using ferroin indicator. COD was calculated using the equation:

$$
\mathrm{COD}(\text { in } \mathrm{mg} / \mathrm{L})=\left(\mathrm{V}_{2}-\mathrm{V}_{1}\right) \times \mathrm{N} \times 8 / \mathrm{X}
$$

Where $V_{1}$ and $V_{2}$ are the volumes of FAS solution consumed by the blank and test sample respectively, $\mathrm{N}$ is the normality of FAS solution and $\mathrm{X}$ is the volume of sample taken for analysis. Table 3 gives the percentages of reduction in COD of $50 \mathrm{mgL}^{-1}$ solutions of dyes on photocatalytic treatment over $\mathrm{Cu}$-doped $\mathrm{TiO}_{2}$ for two hours at $\mathrm{pH} 5$ with catalyst dosage of $1 \mathrm{gL}^{-1}$ and $\mathrm{H}_{2} \mathrm{O}_{2}$ concentration of $0.001 \mathrm{M}$. The reduction in COD values of the treated dye solutions indicates that the mineralization of dyes takes place in a slower rate when compared to the degradation of the dyes.

Table 3. COD removal values for the dye solutions $\left(50 \mathrm{mgL}^{-1}\right)$

\begin{tabular}{cccc}
\hline Dye & $\begin{array}{c}\text { Time of irradiation, } \\
\text { hours }\end{array}$ & \% of Degradation & $\begin{array}{c}\text { \% of Reduction } \\
\text { in COD }\end{array}$ \\
\hline Reactive blue 4 & 2 & 100 & 67.2 \\
Reactive red 120 & 2 & 100 & 64.1 \\
Reactive black 5 & 2 & 100 & 70.5 \\
Reactive orange 30 & 2 & 100 & 76.3 \\
\hline
\end{tabular}

\section{Conclusion}

The Cu-doped $\mathrm{TiO}_{2}$ nanocrystals prepared by sol-gel method show an absorption threshold extended into the visible region. $\mathrm{Cu}$-doped $\mathrm{TiO}_{2}$ samples have higher activity in sun light than the undoped $\mathrm{TiO}_{2}$. Addition of $1 \mathrm{mM}$ of $\mathrm{H}_{2} \mathrm{O}_{2}$ increases the rate of degradation of the dyes. But concentrations beyond $1 \mathrm{mM}$ do not increase the degradation much due to formation of less reactive peroxy radical. Photocatalyst dosage of $1 \mathrm{gL}^{-1}$ was optimum and acidic $\mathrm{pH}$ was more suitable for photocatalytic degradation of anionic dyes. The extent of photocatalytic degradation of the dyes has also been studied by COD measurement.

\section{Acknowledgement}

The authors express their thanks to the authorities of Urumu Dhanalakshmi College for extending their facilities. They also thank the SAIF IIT Chennai for extending their instrumentation facilities for physical measurements.

\section{References}

1. Huang C P, Dong C and Tang Z, Waste Management, 1993, 13(5-7), 361-377.

2. Andreozzi R, Caprio V, Insola A and Martota R, Cat Today, 1999, 53(1), 51-59.

3. Lasa H, Serrano B and Salaices M, Photocatalytic Reaction Engineering; Springer: New York, 2005. 
4. Brijesh Pare, Vijendra Singh and Jonnalagadda S B, Indian J Chem., 2011, 50A, 1061-1065.

5. Zhang Z, Wang C, Zhakaria R and Ying Y, J Phys Chem B, 1998, 102(52), 10871-1078.

6. Zhu J, Deng Z, Chen F, Zhang J, Chen H, Anpo M, Huang J and Zhang L, Appl Catal B: Environ., 2006, 62, 329-335.

7. Zhu J, Zheng W, He B, Jinlong Zhang and Anpo M, J Mol Catal A: Chem., 2004, 216(1), 35-43.

8. Di Paola A, Marci G, Palmisano L, Schiavello M, Uosaki K, Ikeda S and Ohtani B, $J$ Phys Chem B, 2002, 106(3), 637-645.

9. Nagaveni K, Hedge M S and Madras G, J Phys Chem B, 2004, 108(52), 20204-20212.

10. Xiangxin Yang, Chundi Cao, Larry Ericken, Kath Hohn, Ronardo Maghirang and Kenneth Klabunde, Appl Catal B: Environ., 2009, 91(3-4), 657-662.

11. Praserthdam P, Phungphadung J and Tanakulrungsank W, Mater Res Innovations, 2003, 7(2), 118-123.

12. Clark R J H, J Chem Education, 1964, 41(9), 488.

13. Murdoch M, Waterhouse G I N, Nadeem M A, Metson J B, Keane M A, Howe R F, Llorca J and Idriss H, Nature Chem., 2011, 3(6), 489-492.

14. Mohamed M M and Al-Esaimi M M, J Molecular Catal A: Chem., 2006, 255(1-2), 53-61.

15. Zhao W, Fu W, Yang H, Tian C, Li M, Ding J, Zhang W, Zhou Z, Zhao H and Li Y, Nano-Micro Lett., 2011, 3(1), 20-24.

16. Sauer T, Cesconeto Neto G, Jose H J and Moreiral R F P M, J Photochem Photobio A: Chem., 2002, 149(1-3), 147-154.

17. Wang Y and Hong C-S, Water Res., 1999, 33(9), 2031-2036.

18. Malato S, Blanco J, Richter C, Braun B and Maldanado M I, Appl Catal B: Environ., 1998, 17(4), 347-356.

19. Parra S, Stanca S E, Guasaquillo I and Thampi K R, Appl Catalysis B: Environ., 2004, 51(2), 107-116.

20. Regina de Fatima P M M, Ticiane P S, Leonardo C, Eduardo H, J Appl Electrochem., 2005, 35(7-8), 821-829.

21. Daneswar N, Salari D and Khatee A R, J Photochem Photobio A: Chem., 2003, 157(1), 111-116.

22. Wang C C, Lee C K, Lyu M D and Juang L C, Dyes and Pigments, 2008, 76(3), 817824.

23. Macedo L C, Zaia D A M, Moorie G J and De Satana H, J Photochem Photobio A: Chem., 2007, 185(1), 86-93. 